\title{
Efeito do congelamento sobre a imunogenicidade da vacina contra a raiva produzida em tecido cerebral de camundongo
}

\author{
The effect of freezing on immunogenicity of the rabies \\ vaccine produced in suckling mouse brain
}

\author{
Avelino Albas', Rosa Maria Barilli Nogueira², Otávio Luís Fontolan', \\ Kleber da Silva Albas ${ }^{3}$ e Hermann Bremer Neto ${ }^{4}$
}

\begin{abstract}
Resumo A resposta imune humoral induzida pela vacina contra a raiva produzida em cérebros de camundongos recém-nascidos foi estudada em 23 cães e o teste de soroneutralização em camundongos foi usado para avaliação dos níveis de anticorpos rábicos. Um grupo com 10 animais recebeu vacina conservada de 2 a $8^{\circ} \mathrm{C}$ e apresentou os seguintes resultados: após 30 dias da vacinação $6(60 \%)$ amostras responderam ao teste; após 180 dias 4 (40\%) e após 360 dias apenas 1 (10\%). O outro grupo com 13 cães recebeu vacina previamente congelada e somente $2(15,4 \%)$ amostras no dia 30 apresentaram resposta satisfatória; os demais períodos (180 e 360) após a vacinação, não foi encontrado título. A análise estatística dos dados referentes a cada uma das variáveis consideradas no estudo foi efetuada segundo a técnica de análise de variância seguida por Tuckey e indicaram diferenças estatisticamente significativas entre os grupos.
\end{abstract}

Palavras-chaves: Vacina em cérebro de camundongo recém-nascido. Raiva. Soroneutralização. Vacinação.

Abstract The immune humoral response induced by the rabies vaccine produced in suckling mouse brain was studied in 23 dogs. The mouse neutralization test (MNT) was used to evaluate the level of rabies antibodies. Ten dogs received vaccine stored at 2 to $8^{\circ} \mathrm{C}$, showing the following results: 30 days after vaccination, six samples (60\%) responded to the MNT; 180 days after vaccination, 4 samples (40\%); and 360 days after vaccination, only one sample (10\%). The remaining 13 dogs received previously frozen vaccine and 30 days after vaccination, only two samples (I5.4\%) responded to the MNT. No titers were detected 180 and 360 days after vaccination. Statistical analysis of each variable used Tuckey analysis of variance, which showed statistically significant differences between the two groups.

Key-words: Vaccine in suckling mouse brain. Rabies. Neutralizing antibodies. Vaccination.

A vacina contra raiva produzida em cérebros de camundongos recém-nascidos foi desenvolvida no Instituto de Bacteriologia do Chile ${ }^{5} \mathrm{em} 1954$, inicialmente para ser usada em cães. A partir de 1960 sua utilização se estendeu aos humanos e até a presente data a América Latina e Caribe consomem aproximadamente 5 milhões de doses ao ano. Para uso canino são preparadas ao redor de 20 milhões de doses anuais. Portanto, o tratamento preventivo da raiva humana e a vacinação canina são as duas principais ações de controle desenvolvidas no Brasil que possui um Programa Nacional de Profilaxia?
A distribuição da vacina num país como o Brasil pode expor o produto a condições inadequadas de conservação, tanto a altas temperaturas como ao congelamento. Alguns trabalhos científicos têm procurado mostrar a estabilidade deste tipo de vacina em nível de laboratório, observandose as oscilações nos valores antigênicos em função do tempo de estocagem do produto em variadas temperaturas ${ }^{14}$.

Desta forma, este estudo teve por objetivo averiguações em nível de campo, observando-se a resposta imune humoral em cães vacinados contra a raiva com vacina exposta ao congelamento.

\footnotetext{
1. Instituto Biológico, Núcleo Regional de Presidente Prudente; 2. Hospital Veterinário; 3. Faculdade de Medicina; 4. Depto. de Biofísica da Universidade do Oeste Paulista, Presidente Prudente, SP

Endereço para correspondência: Dr. Avelino Albas. Instituto Biológico/Núcleo Regional de Presidente Prudente, Caixa Postal 298, $19101-970$ Presidente Prudente, SP, Brasil.

Telefax: 5518 222-8688.

e-mail: aalbas@bol.com.br

Recebido para publicação em 13/8/99.
} 


\section{MATERIAL E MÉTODOS}

Vacina. Foi utilizada a vacina tipo Fuenzalida modificada (partida 075/97), uso canino, com concentração final $2 \%$ de tecido nervoso de camundongos recém-nascidos, vírus rábico da cepa CVS (Challenge Virus Standard) inativado pela $\beta$-propiolactona e prazo de validade de 1 ano.

Animais. Fizeram parte do experimento 23 cães com idade entre 1 e 3 anos, mantidos no canil da Universidade do Oeste Paulista - UNOESTE de Presidente Prudente$\mathrm{SP}$, sendo todos sem raça definida (SRD).

Teste de soroneutralização em camundongos (SN). Se fez uso deste teste conforme prescrito por Atanasiu², com diluições de soros múltiplas de 5 ; sendo que a amostra cujo resultado foi inferior a 5, considerou-se igual a zero (ausência de resposta imune humoral).

Procedimento. Os animais foram separados em 2 grupos, um grupo de 10 cães recebeu 1 dose de 2,0ml cada de vacina, via sub-cutânea e conservada de 2 a $8^{\circ} \mathrm{C}$; e outro grupo com 13 animais, recebeu igual tratamento, porém com a vacina submetida ao congelamento $\left(-20^{\circ} \mathrm{C}\right)$ por uma noite. Todos os animais foram sangrados nos dias zero, 30, 180 e 360 após a vacinação. Posteriormente, os soros foram separados em alíquotas de $\pm 2,0 \mathrm{ml}$ e em seguida congelados a $-20^{\circ} \mathrm{C}$ até o momento de serem avaliados.

Análises estatísticas. Para análises estatísticas, os títulos individualizados de SN foram submetidos à transformação logarítmica, usando-se $\log _{10}(\mathrm{SN}+1)$ e então analisados por Kruskal-Wallis pelo teste não paramétrico ANOVA. Os valores de SN correspondentes aos dias 30, 180 e 360 foram avaliados pelo teste de regressão linear, adotando $\propto=0.05$, segundo Zar ${ }^{8}$. Os cálculos estatísticos foram feitos pelas médias através do softwere computadorizado GraphPad InStat tm v2.01, e o teste de Tukey-Kramer para comparações múltiplas, quando $q>3.517$, corresponde valor de $P$ menor que 0.05 .

\section{RESULTADOS}

Os resultados dos soros de cães que receberam vacina conservada de 2 a $8^{\circ} \mathrm{C}$ estão expressos na Tabela 1. No dia zero $100 \%$ das amostras não reagiram ao teste; mas 30 dias após a vacinação 6 soros acusaram resultados $\geq 5$, representando $60 \%$ da amostragem. Dentre os cães que foram sangrados 180 dias após, 4 (40\%) deles responderam. Porém aos 360 dias somente 1 (10\%) teve valor $\geq 5$. Nesta Tabela os valores de soropositividade variaram de 5 a 55 .
A Tabela 2 mostra os resultados do teste de soroneutralização em camundongos nos soros de cães que receberam vacina previamente congelada. Pode-se observar que também no dia zero nenhuma amostra reagiu, assim como ocorreu na Tabela 1. No dia 30 somente 2 soros foram positivos, representando 15,4\% da amostragem, porém 180 e 360 dias após a vacinação nenhuma amostra atingiu o valor $\geq 5$. Os valores de soropositividade o mínimo de 5 e o máximo de 11 .

\begin{tabular}{|c|c|c|c|c|}
\hline \multirow[t]{2}{*}{ Animal } & \multicolumn{4}{|c|}{ Tempo em dias } \\
\hline & 0 & 30 & 180 & 360 \\
\hline 1 & 0 & 5 & 0 & 0 \\
\hline 2 & 0 & 0 & 0 & 0 \\
\hline 3 & 0 & 13 & 11 & 0 \\
\hline 4 & 0 & 16 & 5 & 0 \\
\hline 5 & 0 & 0 & 0 & 0 \\
\hline 6 & 0 & 6 & 8 & 0 \\
\hline 7 & 0 & 0 & 0 & 0 \\
\hline 8 & 0 & 0 & 0 & 0 \\
\hline 9 & 0 & 5 & 0 & 0 \\
\hline 10 & 0 & 55 & 25 & 19 \\
\hline Média dos títulos & 0 & 10 & 4,9 & 1,9 \\
\hline$\%$ de títulos $\geq 5$ & 0 & 60 & 40 & 10 \\
\hline
\end{tabular}

Títulos expressos em Dose Eficaz 50

Títulos para $\mathrm{SN}<5$ foram considerados 0 (zero)

O teste não paramétrico ANOVA, por Kruskal-Wallis indicou que houve variações significativas entre médias envolvendo os grupos de cães que recebeu vacina acondicionada de 2 a $8^{\circ} \mathrm{C}$ e congelada, nas colunas referentes aos dias $30(p=0,00228)$ e $180(p=0,0132)$, porém não significativas quanto ao dia $360(p=0,2637)$. 
Tabela 2 - Resultados do teste de soroneutralização em camundongos (SN) em soros de cães que receberam vacina préviamente congelada $\left(-20^{\circ} \mathrm{C}\right)$.

\begin{tabular}{|c|c|c|c|c|}
\hline \multirow[t]{2}{*}{ Animal } & \multicolumn{4}{|c|}{ Tempo em dias } \\
\hline & 0 & 30 & 180 & 360 \\
\hline 1 & 0 & 0 & 0 & 0 \\
\hline 2 & 0 & 5 & 0 & 0 \\
\hline 3 & 0 & 0 & 0 & 0 \\
\hline 4 & 0 & 0 & 0 & 0 \\
\hline 5 & 0 & 0 & 0 & 0 \\
\hline 6 & 0 & 0 & 0 & 0 \\
\hline 7 & 0 & 0 & 0 & 0 \\
\hline 8 & 0 & 0 & 0 & 0 \\
\hline 9 & 0 & 0 & 0 & 0 \\
\hline 10 & 0 & 0 & 0 & 0 \\
\hline 11 & 0 & 11 & 0 & 0 \\
\hline 12 & 0 & 0 & 0 & 0 \\
\hline 13 & 0 & 0 & 0 & 0 \\
\hline Média dos títulos & 0 & 1,60 & 0 & 0 \\
\hline$\%$ de títulos $\geq 5$ & 0 & 15,38 & 0 & 0 \\
\hline
\end{tabular}

Títulos expressos em Dose Eficaz 50

Títulos para $\mathrm{SN}<5$ foram considerados 0 (zero)

Considerando-se as avaliações em cada grupo, e observando a Tabela 1, constatou-se variações significativas somente nas colunas 30 e 60 dias $(p=0,0041)$, sendo que nas demais não houve variações: $30 \times 180(p=0,4088)$ e $180 \times 360(p=0,2034)$. Na Tabela 2, as variações não foram significativas quando do cruzamento das colunas dos dias $30 \times 180(p=0,1586)$ e com igual resultado em
$30 \times 360$. Quando do cruzamento de 180 x 360, houve impossibilidade por serem os resultados todos iguais a zero.

As análises das médias através da regressão linear da Tabela 1 mostrou uma equação de $Y=0,6976$ $0,00157 X$ e $^{2}=0,3813$, na Tabela $2, Y=-0,00041 X+$ 0,12735 , sendo $r^{2}=0,27203$.

\section{DISCUSSÃO}

Os animais usados no experimento não mostraram anticorpos no dia zero. Não se pode concluir com exatidão que os mesmos sejam primo vacinados, porém, passa a ser um bom indicador.

Se for considerado o valor $\geq 5$ como indicador de soro conversão dos cães vacinados, pode-se concluir que o grupo que recebeu vacina estocada de 2 a $8^{\circ} \mathrm{C}$ teve resposta apenas razoável, apresentando $60 \%$ de positividade 30 dias após a vacinação, caindo no dia 180 para $40 \%$ e praticamente inexistindo 1 ano após a vacinação, com apenas 1 animal positivo (10\%) dentre os 10 testados. Estes dados estão próximos aos conseguidos por Haddad et $\mathrm{al}^{6}$ que pesquisaram 29 cães na Tunisia, só obtendo $24 \%$ de títulos favoráveis após 12 meses de vacinação.

No entanto, Chomel et $\mathrm{al}^{3}$ conseguiram ótimos níveis de resposta imune, 97\% das amostras, 1 ano após a campanha de vacinação em massa de cães no Peru em 1985.

Quanto ao segundo grupo, pertinente aos animais que receberam vacina previamente congelada, estocada $24 \mathrm{~h} \mathrm{a}-20^{\circ} \mathrm{C}$, só 2 animais, $15,4 \%$, obtiveram resposta imune 30 dias após a vacinação, sendo que após 180 e 360 dias os resultados foram nulos, evidenciando que o congelamento deste tipo de vacina praticamente inviabilizou a capacidade imunogênica do produto.

Trabalho experimental realizado em nosso laboratório e aguardando publicação, utilizou-se de 2 tipos de vacinas para bovinos em cultivo celular, que após congelamento não apresentaram resultados estatisticamente adversos em relação aos controles, expressos pelos mesmos tipos de vacinas conservadas de 2 a $8^{\circ} \mathrm{C}$, porém estas vacinas não apresentavam fenol como conservante.

Até a presente data, os trabalhos experimentais envolvendo vacinas expostas a condições adversas de temperatura não têm enfocado o aspecto congelamento das mesmas. Este estudo tem por finalidade alertar para maiores cuidados na manutenção dos produtos , assim como, oferecer subsídios técnicos em casos de possíveis congelamentos deste tipo de vacina.

Os resultados deste trabalho experimental demonstraram que a vacina anti-rábica produzida em cérebro de camundongos recém-nascidos, praticamente perde a capacidade de induzir anticorpos neutralizantes quando exposta ao congelamento, e nestas condições, inviabiliza-se o seu uso para cães e possivelmente também para humanos.

No entanto, os autores sugerem a realização de outros trabalhos experimentais neste campo de 
atividades para proporcionar maiores esclarecimentos, entendendo que a pesquisa ora realizada apenas dá inicio às discussões sobre este tema que é por demais abrangente.

\section{REFERÊNCIAS BIBLIOGRÁFICAS}

1. Albas A, Fuches RM, Frazatti Gallina NM, Mendonça RM, Fang $\mathrm{FL}$, Valentini EJ. Termoestabilidade da vacina contra a raiva, tipo Fuenzalida@ Palacios, uso humano. Revista do Instituto de Medicina Tropical de São Paulo 34:27-31, 1992.

2. Atanasiu P. Titulación y prueba de potencia del suero y la inmunoglobulina antirrabicos. In: La Rabia, tecnicas de laboratorio, $4^{\text {th }}$ edition, Organización Mundial de la Salud, Ginebra, p. 332336, 1976.

3. Chomel B, Chappuis G, Bullon F, Cardenas E, David de Beublaint $T$, Lombard $M$, Giambruno $E$. Mass vaccination campaign against rabies: are dogs correctly protected? The Peruvian experience. Reviews of Infectious Diseases 10(supl. IV):S697-S702, 1988.

4. Diaz AM, Perdomo GN, Becco O. Estabilidad de la vacuna antirrabica de cerebro de raton lactante almacenada a distintas temperaturas. Boletin de la Oficina Sanitaria Panamericana, 104, 261-171, 1988.
5. Fuenzalida E, Palacios R. Un metodo mejorado en la preparación de la vacuna antirrabica. [An improved method for the preparation of rabies vaccine.]. Boletin del Instituto de Bacteriologia de Chile 8:3-10, 1955.

6. Haddad N, Blancou J, Gritli A, Ben Osman F, Koutchoukali MA, Aubert MFA. Activité de deux vaccins antirabiques employés lors de la primo-vaccination de chien "tout venant"en Tunisie. Recueil de Medicine Veterinaire 161:755-762, 1985.

7. Schneider MC, Almeida GA, Souza LM, Moraes NB, Diaz RC. Controle da Raiva no Brasil de 1980 a 1990. Revista de Saúde Pública 30:196-203, 1996.

8. Zar H. Biostatistical analysis. International Editions. $2^{\text {nd }}$ edition. Englewood Cliffs, Prentice-Hall, p. 718, 1984. 